\title{
Formation and Development of Agglomeration in Uzbekistan
}

\author{
Muhsin Hidirov, Mavluda Khudoyarova \\ Architecture Department, Samarkand State Architectural and Civil Engineering Institute, Samarkand, Uzbekistan \\ Email: mmhidirov@gmail.com
}

How to cite this paper: Hidirov, M. and Khudoyarova, M. (2021) Formation and Development of Agglomeration in Uzbekistan. Open Access Library Journal, 8: e8134. https://doi.org/10.4236/oalib.1108134

Received: October 29, 2021

Accepted: December 12, 2021

Published: December 15, 2021

Copyright (c) 2021 by author(s) and Open Access Library Inc.

This work is licensed under the Creative Commons Attribution International License (CC BY 4.0).

http://creativecommons.org/licenses/by/4.0/

\begin{abstract}
In urban planning, the system of spatial-territorial location of cities and other populated areas in the country is understood as a joint, interconnected system of settlements. In other words, population distribution is the process of formation cities and villages in a region through the development of existing settlements and the construction of new ones.
\end{abstract}

\section{Subject Areas}

Architecture and Urban Planning

\section{Keywords}

Agglomeration, Settlement System, Socio-Cultural Infrastructure, Service System, Sub-Center, Specialized Centers

\section{Introduction}

The modern settlement system in Uzbekistan has been formed as a result of long-term development, changes in the number of settlements, functional differentiation and integration of the population among them [1]. The dynamics of the population structure in the republic went in the direction of differentiation, which is characterized by a deeper economic specialization of settlements. For this reason, the current location of the population is characterized in the form of cities, urban-type settlements (settlements) and rural settlements, which are formed as simple and constituent centers depending on the performance of administrative functions.

\section{Research}

Population growth in the capital city Tashkent and other major cities creates a 
number of problems, leading to uneven development of productive forces across the country and disproportionate distribution of population. However, urban population growth will continue in the future, and it is important to anticipate development trends in this area. One of the main issues is to study the conditions for the development of group systems of settlements, defining the principles of the field. In general, the Republic of Uzbekistan is characterized by the formation and peculiarities of the location of its settlements (both urban and rural). The following is an overview of the specifics of population distribution. Today, the population of the Republic of Uzbekistan is about 34 million people. It should be noted that there are significant differences in the level of location and urbanization in the country and the regional distribution of population density: the population density in Navoi region is 6 people $/ \mathrm{km}^{2}$, while in Andijan region it is about 500 people $/ \mathrm{km}^{2}$. At the same time, it can be said that the best-developed and most populated areas of the country make up only about $10 \%$ of the total area of the country. This, in turn, is reflected in the distribution of population in urban and rural areas.

The network of cities in Uzbekistan consists of 234 settlements. Of these, 119 are cities and 115 are urban-type settlements. The number of rural settlements is about 12 thousand. Currently, the proportion of urban and rural population is between $47 \%$ and $53 \%$, with a higher rural population. The types of population distribution depend on the specialization of production and the integration of its industries. Types of population distribution, as well as habitats are determined by their size. In the primitive communal system, the division of labor-the separation of handicrafts from agriculture-gave rise to two types of settlement-urban and rural. Even today, there are two main types of population:

- Type of city, associated with the emergence and development of cities and urban-type settlements;

- The type of village is associated with the development of various rural settlements.

Within each species, a number of forms can be distinguished depending on economic, natural, demographic, and other specific conditions. The concentrated view of the urban type of population is typical of large and big cities. The dispersed view of the urban type of population distribution is typical for medium and small cities, as well as urban-type settlements. The form of population distribution depends on the density of the type of settlement, the characteristics of their mutual location within a given area, as well as depends on the level of development of the types of communication between them [2].

Various forms of communication are being formed between the settlements. The second feature of the location of the population is the fact that they are formed autonomously or in groups. In the autonomous form of settlements, cities and villages are located far and apart from each other, communications between them are underdeveloped, transport links are irregular, and functional connections are weak and unstable. In the group form of settlements, cities and villages form a group. Within the group, communications are well developed, 
transport links are regular, functional connections are strong, and settlements have developed regional production links with each other, have a common engineering infrastructure, and are integrated into interconnected system of service and cultural centers. As a group of settlements, cities and villages are combined in a complex way.

In the group system of settlements, the functions of regional centers and inter-district centers are formed in the zone of influence of medium and large cities. In the group system, the time to reach the center is $1.5-2.0$ hours. Depending on the size of the city, the center is divided into three types in the group system of population distribution [3]:

- Large group system, the population of the central city is 500 thousand people and more;

- The average group system, the population of the central city is $100-500$ thousand people;

- Small group system, the population of the central city is 50 - 100 thousand people.

Studies show that the development of urbanization in Uzbekistan has led to the complication of the form of population distribution and urban planning projects. Group living systems are the result of the intensification of economic, labor, cultural, household and other ties between individual urban and rural areas. This indicates the need to improve the living environment not only within the boundaries of individual settlements, but also within the framework of developed urban planning systems-settlement systems. These systems, in turn, are part of the larger sub regional and regional spatial-planning combinations.

\section{Results}

The increase in the population of large and big cities in Uzbekistan creates a number of socio-economic and urban planning problems. Expansion of large and big urban areas is possible due to fertile agricultural lands. As a result, in addition to the cultivation of agricultural products, the environment is degraded by the natural anthropogenic complex and ecology. In addition, the expansion of the urban area poses a number of challenges for the construction and operation of engineering infrastructure.

Due to the uneven distribution of the population in the territory of the republic, the distribution of urban and rural population in the populated areas is not the same. Landscape and climatic conditions in the territory of Uzbekistan contribute to the diversity of the population and the formation of its linear-nodal structure. In the arid climate of the republic, the location and habitat of the population are connected to the plains and river valleys in the middle mountainous areas, as well as to the foothills, where there are sufficient water resources.

In Uzbekistan, as in other countries of the world, group systems of settlements are rapidly developing. GSS (group systems of settlements) are formed on the basis of certain factors. Factors such as the development of urban-rural interactions, the spread of migration processes, the integrated development of the pop- 
ulation network and the development of spatial concepts in urban planning are key factors in the formation of GSS or "agglomerations" [4].

The biggest driving force of urban agglomerations is growth! The main reason for the growth is that people are moving to cities to find attractive living conditions due to population growth. Urban population growth and related housing demand are mainly related to the migration of the rural population from the countryside or elsewhere [5].

\section{Conclusions}

The agglomeration is formed in order to create favorable conditions for life in areas larger than one settlement. The most characteristic feature of agglomeration is the understanding of the spatial unity of social, economic, ecological processes in a single technical and natural environment, which is controlled. Management functions coordinate the activities of all regional systems and ensure their development. The architectural-planning structure of agglomeration at different hierarchical levels to perform management functions is the material elements that ensure the interconnectedness and interdependence of the living environment-settlements, communication routes, production and recreational areas, protected natural and the location of other areas in a particular area is a prerequisite [6].

Agglomerations are formed under the influence of settlements that act as centers. "A settlement that combines collective functions is the center of the system. The center of the system is the focus of gravity for the population and plays a crucial role in the region" [7]. Agglomeration is formed in a series of processes under the constant interaction and decisive influence of the center with its surroundings. Interaction with the center and its surroundings is a prerequisite for the development of settlements, agglomerations and regions. This is an objective law, derived from the essence of modern urbanization. Therefore, it is possible to speed up or slow down the process through targeted actions, but it is not possible to ensure that its development is not disrupted. The development of cities and districts can be influenced by using tools to manage the interaction between the center and its surroundings. In this case, it is possible to accelerate the positive principles of social development processes and prevent negative ones.

\section{Conflicts of Interest}

The authors declare no conflicts of interest.

\section{References}

[1] Tursunov, X.K. (1982) Features and Ways of Development of Urbanization Processes and Settlements in Uzbekistan: Problems of Settlements and Ways of Improvement of Urban Development in Uzbekistan. Tashkent, 24-30.

[2] Yu, S., Popkov, M.V., Posoxin, A.E., Gutnov, B.L., Shmulyan, S.V. and Emelyanova, M. (1983) System Analysis and Problems of Development of Cities. Nauka, 512 p.

[3] Lappo, G.M. (1988) Problems of Study of Urban Agglomerations. In: Lappo, G.M. 
and Listenenrugta, F.M., Eds., Institute of Geography of the USSR, 76 p.

[4] Tursunov, X.K., Bakirkhanov, F.F., Kadyrov, A.B. and Umarov, M. (2006) Conceptual Directions in Development of System of Settlements of Republic of Uzbekistan: Architecture and Construction Problems. TASI, Tashkent, 8-10.

[5] Fang, C. and Yu, D. (2017) Urban Agglomeration: An Evolving Concept of an Emerging Phenomenon. Landscape and Urban Planning, 162, 126-136.

https://doi.org/10.1016/j.landurbplan.2017.02.014

[6] Tursunov, X.K. (2000) Development of System of Settlements of Republic of Uzbekistan as Base for Urban Planning. Tashkent, $65 \mathrm{p}$.

[7] Lappo, G.M. (1974) Geography and Urbanization: Urbanization of the World. 